\title{
OS BOLIVIANOS EM CORUMBÁ-MS: CONFLITOS E RELAÇÕES DE PODER NA FRONTEIRA
}

\author{
Gustavo Villela Lima da Costa
}

A cidade de Corumbá-MS, fundada em 1778, tem em torno de 100 mil habitantes (IBGE 2010) e está situada na fronteira com a Bolívia, a partir das cidades de Puerto Quijarro e Puerto Suarez, em uma região de grande fluxo de pessoas e mercadorias. Ao longo de sua história, Corumbá recebeu migrantes de várias regiões do Brasil e de diversas nacionalidades e etnias, principalmente do Paraguai e da Bolívia, além de sírios, libaneses e palestinos (chamados na cidade de "turcos" ou "árabes"), assim como portugueses e italianos, entre outros.

O rio Paraguai, navegável desde o atual estado de Mato Grosso, passando por Corumbá, Assunção (Paraguai), desaguando no rio Paraná, chegando ao porto de Rosário (Argentina), indo até as cidades de Buenos Aires e Montevidéu, promoveu a circulação de pessoas de diversas nacionalidades pela bacia platina. É preciso ressaltar ainda que esta era (e ainda é) uma região ocupada por etnias indígenas inseridas no que hoje são territórios do Brasil e da Bolívia e que já transitavam, há muito tempo, pelas atuais fronteiras destes países. Além disso, a cidade tem um importante contingente militar (e estatal) que promove uma grande rotatividade de pessoas de vários estados do Brasil, o que implica grande diversidade cultural e social. A fronteira (seja em função da defesa nacional e da presença do aparato estatal, seja pelas oportunidades de negócios) é um dos principais fatores de atração de pessoas para a região e favorece oportunidades de trabalho ou de ascensão social e econômica, sendo utilizada como um recurso material e simbólico por esses atores sociais.

Em 2009, iniciei minhas pesquisas etnográficas em Corumbá, procurando entender principalmente os conflitos entre brasileiros e bolivianos na fronteira em torno do comércio informal (Costa 2010, 2011, 2013a, 2013b, 2014). Os conflitos devem ser vistos, desde Simmel (1964), não apenas em seus aspectos negativos, mas como uma forma de interação social específica, em que as contradições entre as partes envolvidas acabam por criar uma 
espécie de unidade a partir de suas tensões. Outro aspecto muito interessante da obra de Simmel é o fato de que o conflito representa a base para a mudança nas sociedades, o que adquire um matiz específico nas áreas de fronteiras nacionais, como espaços em permanente construção e negociação.

Ao estudar os conflitos, não pretendo negar a importância de outras formas de interação, baseadas em relações de reciprocidade mais horizontais entre brasileiros e bolivianos na fronteira, e muito menos desconsiderar processos de trocas culturais e sociais na região. O que pretendo desvendar são alguns aspectos das relações de poder, que se tornam mais visíveis, empiricamente, por meio da análise dos conflitos sociais. Parto do pressuposto de que as diferenças, ao mesmo tempo em que são formas de classificação, objetificam essas relações de poder.

Essas reflexões estabelecem um diálogo com o pensamento de um dos precursores dos estudos de fronteiras nacionais na Antropologia brasileira, Roberto Cardoso de Oliveira. A respeito das relações entre nacionalidade e etnicidade, ele afirma:

É assim que em ambos os lados da fronteira se pode constatar a existência de contingentes populacionais não necessariamente homogêneos, mas diferenciados pela presença de indivíduos ou grupos pertencentes a diferentes etnias, sejam elas autóctones ou indígenas, sejam provenientes de outros países pelo processo de imigração. Ora, isso confere à população inserida no contexto de fronteira um grau de diversificação étnica que, somado à nacionalidade natural ou conquistada do conjunto populacional de um e de outro lado da fronteira, cria uma situação sociocultural extremamente complexa (Cardoso de Oliveira 2006:107).

A partir desta perspectiva, podemos indagar: Quais as relações que se estabelecem entre identidade, etnicidade e nacionalidade na fronteira Brasil-Bolívia? Como articular a noção de fronteira estatal com as fronteiras sociais e simbólicas na região? Quais os significados dos conflitos entre brasileiros e bolivianos, para além dos fatores econômicos? De que maneira as políticas de segurança e de repressão ao comércio informal e ilegal reproduzem, na prática, discursos e representações sobre o "outro" na fronteira?

Para tentar responder a estas questões, este artigo está dividido em três partes. Na primeira, abordo as interseções entre nacionalidade e etnicidade como critérios de classificação na fronteira e as representações estigmatizantes sobre os bolivianos produzidas no lado brasileiro. Na segunda, discuto as estratégias de trabalho dos bolivianos em Corumbá em torno do comércio informal, relacionando etnicidade e nacionalidade com as oportunidades de trabalho e com as formas de organização social. Por fim, nas considerações 
finais do artigo,busco compreender quais os efeitos sociais da deslegitimação progressiva dos bolivianos no lado brasileiro, manifestados nas políticas de controle e vigilância na fronteira, em torno da criminalização das práticas de trabalho informal.

Dessa forma, pretendo mostrar como os modos de classificar os bolivianos em Corumbá, em conjunto com a situação do trabalho precário e informal a que esses atores sociais têm de recorrer para sobreviver na região, acabam reforçando os estigmas que recaem sobre o grupo. É a partir dessa situação que os coloca como desclassificados sociais, à margem da sociedade, que se legitimam e são postas em práticas as políticas atuais de restrição e controle dos bolivianos, sob o paradigma da legalidade e da segurança pública.

\section{Nacionalidade e etnicidade na fronteira Brasil-Bolívia}

Há nas regiões de fronteiras certamente espaços sociais de circulação, de fluxos e trocas, ou mesmo de "hibridismo" cultural que vão muito além da economia e do dogma da soberania. As fronteiras são espaços de contínua reinvenção identitária e cultural, apresentando um dinamismo próprio. Por sua vez, essas interações na fronteira também são permeadas por conflitos. Existe, então, a construção de discursos e representações que se baseiam no princípio de identidade contrastiva ${ }^{1}$ (Cardoso de Oliveira 2003) e acabam reforçando outras fronteiras sociais e culturais. A noção de fronteira, entendida tanto como limite dos Estados nacionais quanto como construção social e simbólica de limites entre grupos, deve ser pensada em conjunto para dar conta dos fenômenos aqui estudados (Pimenta 2011). A própria fronteira estatal não deve ser "naturalizada", ou seja, analisada como um "dado" em face das outras fronteiras simbólicas e sociais, pois ela também é parte de processos classificatórios, que estão sempre sendo construídos ao longo do tempo. ${ }^{2}$

Torna-se importante entender como se dão os processos de organização social por meio dos quais se mantêm as distinções entre "nós" e os "outros" na fronteira Brasil-Bolívia ao longo do tempo. Em primeiro lugar, observa-se que grupos dominantes, sobretudo no lado brasileiro, impõem seu "poder de nomeação" aos bolivianos, objetivando suas classificações dos "outros", e criam, a partir dos discursos, os próprios grupos sociais e suas hierarquias (Bourdieu 1989). Dessa forma, constata-se uma assimetria de poder na qual está presente a ideia de superioridade-inferioridade manifestada nos discursos e nas práticas do lado brasileiro. Isto estrutura também a construção de preconceitos e de dominação simbólica dos bolivianos, assim como determina as possibilidades de acesso ao trabalho formal e aos direitos. 
A nacionalidade constitui uma categoria central na vida dos moradores fronteiriços, "que organiza o espaço cotidiano, determina o acesso a direitos ou define a situação de estrangeiros, e é condição para tornar-se pessoa na vida local" (Grimson 2003:18). No entanto, diferentemente da fronteira Brasil-Argentina estudada por este autor, a identidade na fronteira Brasil-Bolívia pode ser problematizada não apenas por critérios de nacionalidade (brasileiros/ bolivianos), mas também por critérios étnicos (índios/ não índios). Há uma dupla alteridade do boliviano em solo brasileiro: ao mesmo tempo em que é visto como um "outro" nacional (estrangeiro), é representado como um "outro" indígena, duplicando, em grande medida, o estigma social que recai sobre o grupo. Grande parte dos migrantes e residentes bolivianos na fronteira tem, de fato, sua origem nos Aymara ou nos Quéchua (do altiplano), além dos Kambas e dos Chiquitanos, das terras baixas.

Como se operacionalizam, nesse contexto, tais distinções étnicas? De que forma a etnicidade constitui um critério de hierarquização e organização social na fronteira Brasil-Bolívia? Para responder a estas questões, faremos uma breve revisão do conceito de etnicidade nos trabalhos de Fredrik Barth e Roberto Cardoso de Oliveira.

Para Barth (2000), são as fronteiras, a partir de processos de exclusão e inclusão, e não o conteúdo cultural, que definem os grupos étnicos e explicam sua persistência. Nas palavras do autor, "torna-se claro que as fronteiras étnicas permanecem apesar do fluxo de pessoas que as atravessam" (Barth 2000:26), ou seja, as distinções étnicas dependem justamente da interação social com o "outro" e não de uma diferença "naturalizada" ou anteriormente definida pelos contrastes culturais. Portanto, a identidade étnica é construída e transformada na interação entre os grupos sociais, contribuindo para organizar, inclusive, o teor dessas interações. Outro ponto importante levantado por Barth diz respeito à "atribuição" e aos critérios de pertencimento como características fundamentais da etnicidade. Segundo o autor, a distinção étnica ocorre quando uma pessoa se vê como parte de um grupo étnico distinto e assim é vista, em função de critérios específicos, por aqueles que não fazem parte do grupo.

De maneira semelhante a Barth, Roberto Cardoso de Oliveira (2003) aponta a importância do contato para a diferenciação étnica, que não se baseia nunca em uma "essência" que distinguiria os grupos sociais. Observa-se, então, como os atores sociais identificam-se e são identificados por outros nessas regiões em situações de "cultura do contato", isto é, num "conjunto de representações (em que se incluem também os valores) que um grupo étnico faz da situação de contato em que está inserido e nos termos da qual classifica (identifica) a si próprio e os outros" (Cardoso de Oliveira 2003:130). 
O autor acrescenta ao debate a dimensão do conflito e das assimetrias de poder nessas interações, assim como a ideia de que a identidade étnica pode ser manipulada por atores sociais em situações ambíguas, como as fronteiras nacionais. Para Cardoso de Oliveira, as propriedades estruturais do processo de identificação étnica são:

a) o caráter contrastivo da identidade étnica e seu forte teor de "oposição" com vistas à afirmação individual ou grupal;

b) sua manipulação em situações de ambiguidade, quando se abrem diante do indivíduo ou do grupo alternativas para a "escolha" (de identidades étnicas) à base de critérios de "ganhos e perdas" (critérios de valor e não como mecanismos de aculturação) na situação de contato (:131).

A manipulação das identidades em áreas de fronteira é muito importante para entendermos, por exemplo, os processos de adaptação dos bolivianos em Corumbá e seu acesso a serviços, como atendimento à saúde e à educação, sobretudo no caso dos indivíduos que possuem dupla nacionalidade. Isto demonstra também que as identidades nunca são rígidas e monolíticas, ainda mais nas fronteiras, entendidas como espaços liminares.

Devido à situação dos bolivianos em Corumbá, considerados ao mesmo tempo "estrangeiros" e "índios" pelos brasileiros, há grandes semelhanças com o processo de contato interétnico entre índios e não índios no Brasil, embora essa interação nas fronteiras não ocorra apenas no interior do mesmo espaço nacional (como é o caso do contato interétnico entre índios e a sociedade nacional).

A ideia de "fricção interétnica" (Cardoso de Oliveira 2003, 1976), por exemplo, que ocorre em um sistema inter e transnacional, nos permite entender a fronteira como um local de contato entre grupos nacionais (e não apenas grupos étnicos) "irremediavelmente vinculados, em suas contradições, a partir justamente de seus conflitos (manifestos) e suas tensões (latentes)" (Cardoso de Oliveira 2003:120). Esses conflitos e tensões, engendrados pela fricção de etnias e nacionalidades postas em conjunção, estruturam a vida social na fronteira e forjam as diferenças e as hierarquias entre grupos. Se a etnicidade é uma forma de interação entre grupos operando no interior de contextos sociais comuns, "as áreas de fronteira (como as áreas de fricção interétnica, noutro momento) representam contextos privilegiados para a descrição e a análise da produção social da diferença nacional" (Silva 2007:342).

Um dos maiores desafios de nossas pesquisas etnográficas é trabalhar com essas interações sociais (entre nacionalidades e etnias) na fronteira como um espaço de ambiguidade e tensão, entendidas não apenas em seus 
sentidos negativos, pois também favorecem processos criativos de interação e reinvenção cultural e identitária.

Muitos indivíduos de origem boliviana são nascidos em Corumbá e ilustram bem essa situação intersticial de suas identidades. Essas pessoas possuem os documentos de identidade brasileiros, estudam nas escolas brasileiras, prestam o serviço militar obrigatório, são bilíngues, em sua maioria, mas continuam sendo chamados de bolivianos pelos brasileiros. Como muitos desses atores sociais vivem no lado boliviano da fronteira, continuam a manter os laços culturais e identitários com a Bolívia, identificando-se, em muitas ocasiões, como bolivianos e não como brasileiros (mesmo que nascidos no Brasil). Algumas professoras de Corumbá relataram que os alunos "bolivianos" sabem mais de feriados e datas históricas da Bolívia do que do Brasil (Moraes 2012). Em algumas ocasiões, entretanto, esses indivíduos acionam suas identidades de "brasileiros", sobretudo quando necessitam de serviços e direitos do lado brasileiro da fronteira, como acesso à educação, à saúde, à moradia e ao trabalho.

A geografia peculiar dessa fronteira, cercada pelo Pantanal, em relativo isolamento, intensifica a interdependência entre brasileiros e bolivianos, já que as cidades de Corumbá e Ladário, ${ }^{3}$ no lado brasileiro, e Puerto Quijarro e Puerto Suarez, no lado boliviano, estão distantes dos principais centros urbanos, seja de Campo Grande (450 km), seja de Santa Cruz de La Sierra (mais de $600 \mathrm{~km}$ ). O insulamento dessas cidades contribuiu para forjar uma figuração social específica (Elias 2006), ${ }^{4}$ além de estilos de vida, representações e padrões de interação muito peculiares ao longo do tempo. Na BR-262, que corta o Pantanal, há uma placa que indica simbolicamente o peso da distância, na cidade de Miranda (a $200 \mathrm{~km}$ a leste de Corumbá): próximo posto de gasolina a $150 \mathrm{~km}$. Nesse trecho, a estrada construída como um aterro avança sobre a imensidão do Pantanal, não há sinal de celular e há pouquíssima presença humana. Mas não nos enganemos, aí passam caminhões, mercadorias e pessoas, em um fluxo intenso através da fronteira (além da rodovia, das ferrovias, da hidrovia e dos aeroportos).

Nessa situação de interdependência entre essas cidades, há uma negação histórica da condição de cidade fronteiriça por parte dos moradores de Corumbá, resumida na frase: "a fronteira é lá, e não aqui". Os corumbaenses associam a fronteira à Bolívia e a identidade de fronteiriços apenas aos bolivianos. Essa separação não é apenas simbólica, mas física também. Entre o centro da cidade de Corumbá e a linha de fronteira, em Arroyo Concepción, distrito de Puerto Quijarro, percorrem-se aproximadamente $5 \mathrm{~km}$ na rodovia Ramon Gomez, que segue paralela ao canal do Tamengo, no lado direito (que liga o rio Paraguai à baía Cáceres, no lado boliviano). 
Do lado esquerdo, fica a pista do aeroporto de Corumbá e depois o cemitério Nelson Chamma, antes do pedágio. Daí em diante, até a linha de fronteira quase todos os terrenos estão situados em área militar ou estatal e não há construções em uma área de mata fechada. Cercas de arame farpado separam os territórios nacionais próximos à linha divisória.

As últimas construções no lado brasileiro são o Clube Recreativo de Subtenentes e Sargentos (Cresse) e as instalações da Receita Federal e da Polícia Federal, que são prédios de instituições de controle e vigilância. Essa paisagem e esse ordenamento urbano não se construíram ao acaso e visam ao controle soberano da linha de fronteira pelo Estado brasileiro, além de proibir a ocupação dos terrenos próximos à fronteira, com o objetivo de impedir que as cidades de Corumbá e Puerto Quijarro se conurbem totalmente, tornando-se uma só cidade.

A própria situação de liminaridade coloca a fronteira, cujo status possui algo de "indefinível" e ambíguo, como um local "vulnerável e perigoso" simbolicamente, por romper com a estabilidade ideal dos sistemas culturais (Douglas 2012:119). Os bolivianos, sobretudo aqueles que dependem de cruzar diariamente a linha divisória entre os países para sobreviver, vivenciam em Corumbá uma situação ambígua e marginal (no sentido de estarem à margem da sociedade, principalmente no que se refere aos direitos), nos interstícios das estruturas de poder, muitas vezes nos limites entre o legal e o ilegal.

Nessa fronteira, que o Estado brasileiro quer manter relativamente afastada e controlada, podemos considerar que os bolivianos também estão cruzando fisicamente barreiras sociais quando circulam entre Puerto Quijarro e Corumbá. Ao mesmo tempo em que estão excluídos do padrão social vigente, representam uma "ameaça" simbólica às pessoas com status mais definidos. De acordo com Douglas (2012):

O perigo está nos estados de transição, simplesmente porque a transição não é nem um estado nem o seguinte, é indefinível. A pessoa que tem que passar de um a outro está ela própria em perigo e o emana a outros. O perigo é controlado por um ritual que precisamente a separa do seu velho status, a segrega por um tempo e, então, publicamente, declara seu ingresso num novo status [...] ter estado nas margens é ter estado em contato com o perigo, é ter ido à fonte do poder (:119-20).

Nesse processo de representação da alteridade na fronteira, a construção negativa do "outro" sustenta a própria identidade brasileira, ou seja, o boliviano se constrói no imaginário brasileiro fora dos parâmetros que 
definem os valores "civilizados". Nesse contexto, a imagem do "outro" ganha contornos específicos em Corumbá, na medida em que a Bolívia é vista por parte da população como símbolo do atraso, da pobreza e da falta de "civilidade", de higiene, das leis. Esses estigmas podem ser resumidos nas categorias identitárias de "chocos", "collas" ou simplesmente "índios" ou "bugres". Percebe-se, em inúmeras conversas com moradores de Corumbá, que a Bolívia é representada como um lugar "sem lei" e "corrupto". "Você já dirigiu na Bolívia? Lá não tem lei, cada um faz o que quer. E a polícia lá? São todos corruptos... qualquer coisinha errada querem dinheiro... e quando eles vêm aqui, não querem seguir as leis... no Brasil a lei é pra todo mundo".

Outra categoria que aparece recorrentemente em Corumbá sobre a Bolívia e os bolivianos é o binômio sujeira/doença. Existe uma visão difusa no lado brasileiro que considera que os bolivianos "não têm higiene" e, por conseguinte, as cidades bolivianas fronteiriças seriam foco de doenças. Enfermidades como a raiva, a leishmaniose e a dengue aparecem como problemas não tratados no lado boliviano, o que produz o discurso da fronteira como área de contágio, na qual a enfermidade representa "um signo de corrupção física e moral, um signo de falta de civilização" (Hardt \& Negri 2000:132).

Três casos, que presenciei, ilustram essa imagem difusa na sociedade corumbaense (Costa 2013a). ${ }^{5}$ Eu passeava com meu cachorro e perguntei a um rapaz sobre possíveis surtos de leishmaniose na cidade. O rapaz apontou na direção da Bolívia e me disse "vem tudo de lá. Aqui é fogo... lá não tem controle. Esses bolivianos são muito porcos!". No ano seguinte eu contraí dengue e ainda não sabia que estava doente quando fui realizar um trabalho de campo em Santa Cruz de La Sierra, na Bolívia. A doença se manifestou nesta cidade, e eu retornei a Corumbá para o tratamento. Muitas pessoas disseram "pegou dengue na Bolívia...". Um terceiro exemplo pode ser encontrado em entrevista, quando uma moradora de Corumbá afirmou que, quando criança, ao cruzar a fronteira para Puerto Quijarro, sua mãe a obrigava a prender o cabelo, para evitar o contágio de piolhos, e continuou, "assim que chegávamos em casa, éramos obrigados a tomar banho imediatamente". Estes exemplos expõem as representações sociais no lado brasileiro que consideram a fronteira como área de contágio, em que o banho aparece simbolizando um ritual de "limpeza" desse contato com o outro que se quer evitar. O boliviano como cruzador de fronteiras físicas e sociais torna-se, simbolicamente, "um poluidor duplamente nocivo, primeiramente porque cruzou a linha e, em segundo lugar, porque colocou as pessoas em perigo" (Douglas 2012:170).

A questão da estética aparece nos discursos como mais um critério de classificação social. Em geral, as pessoas do lado brasileiro se referem 
a Puerto Quijarro como um lugar "feio", em contraposição à "beleza" de Corumbá, vista como polo turístico. A noção de feiúra nesses discursos se estende também aos próprios bolivianos e não apenas ao lugar. Ao longo do tempo, escutei de alunos e alunas da graduação da UFMS, em geral em tom de brincadeira nos corredores da Universidade, as seguintes frases: "Você é boliviana... não engana ninguém... é bugra!"; em outra ocasião uma mulher se sentiu ofendida ao ouvir um elogio, seguido da pergunta sobre sua origem (tanto indígena quanto boliviana): "Você é bonita! Tem um cabelo de índia, né? Você é descendente de bolivianos?". Em uma entrevista, uma moradora de Corumbá exemplifica essa representação sobre beleza/feiura em relação a critérios étnicos ao associar o boliviano a um fenótipo específico e estigmatizado: "Minha amiga namora um boliviano. Mas ele é bonito. É branco, de Santa Cruz, tem olhos claros e tudo! Nem parece boliviano... Deus me livre namorar um choco desses aí...".

Mais uma categoria discursiva presente na vida social de Corumbá é aquela que associa o boliviano à "pobreza". Esses discursos são muito semelhantes aos que identificou Vila (2000), na fronteira do México com os Estados Unidos, nas cidades de El Paso (Estados Unidos) e Ciudad Juarez (México), em que os estadunidenses produzem um discurso de que "All poverty is mexican" ("toda pobreza é mexicana") (Vila 2000:86). Essa vinculação dos bolivianos a uma classe específica, vistos como "pobres", gera inúmeros discursos de "benevolência" do poder público brasileiro como "benfeitor" dos bolivianos, seja no atendimento de saúde, seja na matrícula nas escolas (em uma pressuposição tácita de superioridade e de que "eles" dependem de "nós").

Podemos pensar nas representações sociais construídas entre brasileiros e bolivianos na fronteira a partir da leitura de Mary Douglas (2012). A autora, estudando os rituais de passagem, utiliza os conceitos de "pureza" e "perigo" e as antinomias como pureza/impureza, limpeza/sujeira, contágio/purificação, beleza/feiura e ordem/desordem como ferramentas para compreender a ordem social e as representações da alteridade. Em grande medida, as construções sociais e as representações do outro na fronteira são forjadas a partir dessas antinomias, como se nota nos recorrentes discursos sobre as convenções sociais a respeito da "higiene". Douglas afirma que a sujeira é relativa e que representa "essencialmente desordem. Não há sujeira absoluta. Ela existe nos olhos de quem vê" (:12). A autora entende que as concepções sobre sujeira e poluição se inserem em um diálogo de reivindicações de status social, em função das convenções sociais, a partir das quais algumas poluições são "usadas como analogias para expressar uma visão geral da ordem social" (:14). 
De forma análoga, os brasileiros produzem discursos a respeito desse encontro cultural com o "outro" na fronteira como foco de um "contágio" ou "perigo" que se quer evitar, ou seja, como uma reação etnocêntrica a uma suposta ameaça às normas ideais do grupo (associadas aos discursos de nacionalidade), calcadas na ideia de pureza e na "segurança" do próprio sistema cultural, avesso às contradições. Cruzar a fronteira é sair da "zona de conforto", obrigando seus moradores a entrarem diretamente em contato com outros sistemas sociais e culturais e, portanto, se torna um "ato de poder" (Douglas 2012) carregado de significados e que estrutura a ação social, a interação e as relações sociais entre os grupos que aí interagem, em um cenário de forte alteridade.

Autores que estudaram a dinâmica migratória da Bolívia para a Argentina também identificaram formas de preconceito em relação aos bolivianos (preconceito cultural, racial e social), a partir das quais se produzem representações sobre a "falta de higiene" e de "cultura" dos bolivianos, chamados por algumas pessoas de maneira estigmatizante de "bolitas" na Argentina. Benencia e Karasik (1996), por exemplo, narram a expulsão de imigrantes bolivianos da fronteira argentino-boliviana, considerados pelas autoridades locais como responsáveis pela epidemia de cólera na região nos anos de 1990, por causa de seus supostos "costumbres". Destaca-se também a percepção, por parte dos autores, da existência de uma "dupla alteridade" dos bolivianos em solo argentino (estrangeiros e indígenas), de maneira semelhante ao que descrevo na fronteira em Corumbá (ver Grimson 1997; Benencia 2004; Karasik \& Benencia 1998; Benencia \& Karasik 1996; Karasik 2012). Além disso, processos semelhantes de estigmatização e hierarquização social em relação aos migrantes paraguaios fronteiriços são descritos e analisados na fronteira Argentina-Paraguai por Betrise e Nadali (2007).

Algumas das representações sociais baseadas em assimetrias de poder na fronteira relacionam os bolivianos às práticas ilegais em Corumbá. Esse preconceito pode ser notado a partir de discursos difusos entre a população e de alguns interlocutores, como o de um mototaxista da cidade que entrevistei e que nos serve de exemplo. Já que havia estudado anteriormente os conflitos entre taxistas brasileiros e bolivianos na fronteira (Costa 2011), perguntei ao mototaxista sobre os possíveis conflitos existentes entre os mototaxistas oficiais e os "clandestinos" na cidade. Isto porque, do mesmo modo que os taxistas estão cadastrados pela prefeitura, há um sistema oficial de trabalho dos mototaxistas em Corumbá, que pagam por suas licenças e usam um colete e capacetes amarelos que os identificam, autorizando-os a pegar passageiros na rua. Além disso, eles estão distribuídos em pontos pela cidade. Apesar dessa regularização, há inúmeros motoqueiros que cobram 
para levar passageiros de maneira independente, portanto de modo irregular, do ponto de vista da prefeitura e dos mototaxistas cadastrados. Eu indaguei a J., um mototaxista cadastrado, se havia muitos bolivianos pilotando motos e transportando passageiros de maneira "clandestina", já que a maioria dos mototaxistas não cadastrados na cidade é de brasileiros (ao contrário dos taxistas "ilegais", de origem boliviana).

Tem uns bolivianos que trazem passageiros lá da Bolívia. Eles tiram os coletes e trazem. Mas não é muito não. Os clandestinos são brasileiros mesmo. Só que a população de Corumbá, se você for ver, é tudo bolivianado, tem mãe, avó boliviana... e aí eles preferem fazer tudo ilegal também. Eles são assim... são criados desse jeito.

Continuamos a conversar e o mototaxista me contou como achava caro pagar as taxas da moto exigidas pela prefeitura de Corumbá e que por isso não comprava nada da moto no Brasil. "Essa moto tem cinco anos e eu nunca coloquei gasolina no Brasil! Eu me recuso a dar dinheiro pro governo brasileiro. Só compro gasolina na Bolívia. Compro pneu lá... tudo. Vou comprar aqui pra quê?".

Notamos na fala do mototaxista dois aspectos que nos parecem mais relevantes. Quando se refere à população "bolivianada" de Corumbá como uma razão para as práticas ilegais, J. pressupõe haver uma natureza "degenerada" dos bolivianos, como se os atos ilegais decorressem da "índole" determinada pelo "sangue" de parte da população que se recusaria a cumprir a lei por ter origem boliviana. Novamente observamos o recorrente racismo e a associação das práticas irregulares na fronteira com os bolivianos, cuja própria condição de moradores no lado brasileiro é tida como ilegal e cujas posições de trabalho são vistas como a de concorrentes.

Entretanto, logo em seguida, o próprio J. afirma comprar gasolina ilegalmente na Bolívia, pois se sente "roubado" pelo governo brasileiro ao pagar muitos impostos. Nesse sentido, J. produz uma justificativa moral e econômica para comprar gasolina na Bolívia, escapando à classificação de ilegal atribuída pelo próprio mototaxista aos bolivianos. Os ilegais são os "outros", e algumas práticas nas margens da legalidade feitas por ele seriam aceitas e justificadas pelo fato de o Estado brasileiro "cobrar muito e não dar nada em troca". Outro aspecto fundamental presente implicitamente em sua fala é o das representações sobre a Bolívia, os bolivianos e a fronteira por sua utilidade (ou seu aspecto de recurso de sobrevivência). A fronteira aparece primordialmente nesses discursos como um lugar útil, onde se fazem compras, ou ainda como se sua utilidade fosse uma compensação pelo fato 
de se ter de conviver com vizinhos indesejáveis ou com os problemas que parte dos moradores de Corumbá acredita emanarem da fronteira, como crimes, enfermidades e miséria social.

Outros casos demonstram de que forma ocorre a reprodução social dos preconceitos na fronteira. Tomemos como exemplo a situação das crianças de origem boliviana na cidade de Corumbá (as quais podem ser filhos de pais bolivianos, embora nascidas no lado brasileiro) que tem gerado algumas pesquisas no MEF (Mestrado em Estudos Fronteiriços da UFMS). Em um estudo de caso, em uma escola pública de Corumbá, um aluno de origem boliviana, filho de mãe brasileira e pai boliviano, pediu ao seu pai para que não o buscasse mais na escola, pois temia as brincadeiras preconceituosas dos colegas, com vergonha pelo fato de seu pai ser boliviano (Ribeiro 2011). As pesquisas realizadas nas escolas de Corumbá demonstram que o preconceito em relação aos bolivianos é explícito, seja pelo bullying, ou por outras formas de discriminação (Ribeiro 2011; Moraes 2012). Um caminho interessante de pesquisas se abre permitindo novos diálogos com Roberto Cardoso de Oliveira, quando ele trabalha com a noção de "identidade negativa", no contato entre índios e não índios:

Dentre as compulsões desagregadoras que mais eficazmente afetam os grupos indígenas em contato sistemático com a sociedade nacional, estariam as que atingem diretamente os seus contingentes infantis. A permanência contínua em situações de discriminação desperta desde cedo nas crianças uma consciência negativa de si ou, em termos de Erikson, uma "identidade negativa" que se prolongará na juventude e maturidade, raramente transformável numa identidade positiva capaz de auxiliar o indivíduo ou o grupo a enfrentar situações críticas (Cardoso de Oliveira 2003:127).

Há, portanto, uma questão de dupla alteridade do boliviano, como estrangeiro e indígena. Retomamos a análise de categorias como "bugre" ou "índio" e sua importância no "sistema classificatório" de Mato Grosso do Sul (com a segunda maior população indígena do Brasil), e que tem para amplos setores sociais não índígenas um sentido pejorativo, seja nos discursos, muito semelhantes às representações descritas acima em relação aos bolivianos (sujeira, preguiça, indolência, feiura, doença etc.), seja na prática, a partir da difícil situação fundiária do estado, com a constante expulsão dos indígenas de suas terras, a violação dos direitos humanos e a violência no campo. Em grande medida, o índio representa para as elites políticas de Mato Grosso do Sul a imagem do "atraso", associado ainda a um "estado de natureza", que deve ser domado, civilizado e desenvolvido com o avanço da fronteira 
do Estado brasileiro, objetivado, atualmente, pelo agronegócio. Assim, os bolivianos (vistos do lado brasileiro como sinônimo apenas de suas etnias do altiplano) representam nesse contexto local um "outro" indesejado, uma fronteira que deve ser mantida como limite, como barreira.

\section{Etnização dos bolivianos em Corumbá}

A partir do que foi exposto até aqui se percebe que os bolivianos em Corumbá formam minorias, "grupos diferenciados no âmbito das sociedades globais, em posições subalternas" (Cardoso de Oliveira 2005:9). Entende-se que as etnias em um contexto de fronteira nacional devem ser consideradas não apenas em si mesmas, mas inseridas em outro quadro de referência: o quadro (inter)nacional. Esse quadro é marcado por um processo transnacional, cujo determinador social, político e cultural passa a ser a nacionalidade, mais do que a etnicidade, cuja ambiguidade abre espaço para a manipulação das identidades étnicas e nacionais em conjunção (Cardoso de Oliveira 2006:108). Os bolivianos como minorias étnicas e nacionais na cidade de Corumbá passam por um processo constante de etnização de suas identidades nacionais quando entram em território brasileiro:

\footnotetext{
Naturalmente, falar de etnização é socorrer-nos do conceito de etnicidade [...] definido como envolvendo relações entre coletividades no interior de sociedades envolventes, dominantes, culturalmente hegemônicas e onde tais coletividades vivem a situação de minorias étnicas ou, ainda, de nacionalidades inseridas no espaço de um Estado-nação (Cardoso de Oliveira 2006:89).
}

A partir da leitura de Hannerz (1974), podemos pensar nas relações que se estabelecem entre etnicidade e oportunidades sociais e de trabalho no ambiente urbano de Corumbá. Hannerz entende que os grupos étnicos urbanos podem ser estudados como "grupos de interesse" (interest groups), em disputa com outros grupos pelos recursos na arena pública. A etnicidade e, no caso da fronteira, a nacionalidade também são "idiomas" que promoveriam a solidariedade entre os indivíduos como um dever moral (Hannerz 1974:39). São inúmeras as questões que surgem em nossos estudos a partir da compreensão das relações entre etnicidade, nacionalidade e relações de trabalho na fronteira.

Quando nos referimos ao trabalho informal, basicamente no comércio, destacamos os seguintes locais de trabalho, em Corumbá, por sua importância e volume de mercadorias: as feiras de rua itinerantes, onde predominam os 
hortifrutis (cultivados no lado boliviano e nos assentamentos rurais no lado brasileiro), roupas, CDs, peças de bicicleta, fraldas, brinquedos, em sua maioria "Made in China", trazidos da Bolívia; a Feira Bras-Bol (espécie de camelódromo local, que foi fechada em 2013, onde predominava a venda de roupas e calçados), ou as "lojinhas" (estes são pontos de comércio fixo, em imóveis urbanos de Corumbá, com os mesmos produtos da Feira Bras-Bol). Existem ainda os camelôs de rua, em número mais reduzido, e os vendedores de artesanatos bolivianos para turistas, especialmente na porta dos hotéis. Grande parte desses pontos de comércio informal é ocupada por bolivianos, o que vem gerando reações do poder público, apoiadas por setores sociais e econômicos da cidade de Corumbá, principalmente pela Associação Comercial (Costa 2013b).

Em uma entrevista com um taxista brasileiro na cidade de Corumbá, escutei o seguinte argumento:

Eu já fui contrabandista, não nego! Trazia direto mercadoria contrabandeada da Bolívia... até que me pegaram! E essa bolivianada aí passa todo dia dizendo que é feirante... todo mundo é feirante agora... não sou contra eles trabalharem, mas a lei tem que ser pra todos. Por que eles podem vender e a gente, brasileiro, não? Vai você vender... aí pra você ver!

Essa fala do taxista aponta para uma importante questão na fronteira, revelando conflitos em torno do comércio informal, que é percebido por moradores de Corumbá como feito apenas por bolivianos. Embora esse comércio não seja exclusivamente feito por eles, como veremos neste artigo, há algumas razões que explicam sua predominância no comércio de rua em Corumbá, assim como sua maior visibilidade. De fato, a atividade de comércio informal feita por bolivianos é mais visível em Corumbá por se tratar de feiras e comércios de rua e pelos critérios de classificação do lado brasileiro, a partir dos quais os "marcadores sociais da diferença" contribuem para a divisão entre "nós" e "eles" (modos de vestir — as tranças e as roupas coloridas das mulheres bolivianas, os modos de falar - espanhol, quéchua, aymara - técnicas de corpo e assim por diante).

Além disso, de fato, os bolivianos exercem um "contrapoder" em que passam a ocupar o comércio informal de rua em Corumbá mediante estratégias de passagem de mercadorias (principalmente a passagem diária de pequenas quantidades), nas chamadas "competências circulatórias" (Telles 2009), ${ }^{6}$ negociando mercadorias a preços mais baixos (em função da moeda boliviana valer menos) e negociando sua permanência no espaço de rua junto às autoridades brasileiras (como foi o caso da Feira Bras-Bol, 
que funcionou na semilegalidade por mais de 20 anos na cidade). A própria cidade de Corumbá depende do abastecimento de produtos do outro lado da fronteira, como é o caso de hortifrutis nas feiras da cidade, assim como de roupas, eletrodomésticos, entre outros.

Isto não significa que brasileiros não tenham lojas em que possam vender roupas não tributadas, ou que não sejam sócios de bolivianos nesses negócios. Quando constatamos que grande parte do comércio informal na fronteira é realizada por bolivianos, isto não quer dizer que não existam brasileiros trabalhando com mercadorias não tributadas na cidade, cruzando a fronteira com mercadorias ilegais, ou mesmo participando ativamente desse comércio na fronteira. O que notamos em nossas pesquisas é que a maior parte dos brasileiros envolvidos no comércio de roupas não tributadas, no comércio popular, são os sacoleiros que, em geral, não vivem em Corumbá. Assim, utilizamos, a partir de Oliveira (2013), a distinção entre os comerciantes que vivem na fronteira, como é o caso dos feirantes da Bras-Bol, e os comerciantes que vivem $d a$ fronteira e que vão levar esses produtos para o interior do Brasil, como é o caso dos sacoleiros.

Em entrevista com um dos poucos feirantes brasileiros, ${ }^{7}$ que vende roupas "Made in China" nas feiras de rua, pudemos entender alguns aspectos da interação entre comerciantes brasileiros e bolivianos. Chamou-nos a atenção, em sua entrevista, como ao longo do tempo na convivência diária do trabalho na feira o entrevistado mudou a forma pela qual representava os bolivianos: de concorrentes a compadres, de rivais a parceiros comerciais. Foi possível perceber também como a partir dos laços sociais, como o compadrio, o entrevistado conseguiu melhores acordos comerciais, para além das trocas culturais e dos laços afetivos e pôde se estabelecer como comerciante de roupas na fronteira.

Quando comecei há dez anos atrás, eu não gostava dos bolivianos... achava que eles estavam invadindo nosso espaço. Nem falava com eles e ia brigar direto na prefeitura. Até que um tiozinho da banca do lado veio falar comigo: "você acha que nós somos seus concorrentes? Você está mirando no inimigo errado... nós estamos juntos. Nós não somos inimigos". As palavras dele ficaram na minha cabeça. E aí eu vi que era verdade. Hoje a gente luta pra permanecer na feira trabalhando contra essas pressões aí. Os bolivianos são gente boa, depois que você entende eles... hoje sou amigo deles, vou na Bolívia direto, almoçar na casa de amigos, nas festas... Sou padrinho de um monte de crianças. Lá eles têm padrinho pra tudo: formatura, nascimento, 15 anos... então hoje trabalhamos juntos, entende? 
As relações sociais que se constroem entre brasileiros e bolivianos, como o compadrio, no exemplo acima, propiciam o cruzamento das fronteiras étnicas e nacionais por parte de alguns atores sociais, reinventando suas identidades nesse processo. O cruzamento de tais "muros invisíveis" tem benefícios práticos também: por parte dos comerciantes brasileiros, facilita a aquisição de mercadorias por menor custo e potencializa as "competências circulatórias" para cruzar a fronteira com as roupas para Corumbá; os bolivianos, por sua vez, ganham mediadores brasileiros diante do poder público e aliados na proteção de seus postos de trabalho, além de consumidores brasileiros indicados pelo compadre, por exemplo. O compadrio adquire, então, um aspecto político, como uma estratégia de proteção social na fronteira, ao propiciar a entrada do brasileiro em um circuito de reciprocidade e solidariedade junto a um grupo minoritário. ${ }^{8}$ Este tipo de relação social proporciona a defesa conjunta de interesses e, do ponto de vista econômico, favorece o comércio a partir da formação de redes de confiança, crédito, reciprocidade e obrigação entre indivíduos dos dois lados da fronteira.

Esse feirante pode ser considerado como parte de uma minoria entre os comerciantes informais brasileiros nos comércios populares de rua em Corumbá. O que se observa é que os brasileiros que se dedicam ao comércio informal em Corumbá tendem a utilizar suas casas como extensão para seus negócios seja para realizar "promoções" (vendas antecipadas de almoços ou comidas entre vizinhos), ou para vender lanches (hambúrgueres ou cachorros-quentes), seja para abrir um salão de corte de cabelos, bicicletarias ou outros serviços. Nesses pequenos negócios caseiros também se extrai o lucro com passagem de mercadorias na fronteira, porém em menor escala. Em geral, são produtos comprados na Bolívia e que servem para o trabalho, como, por exemplo, óleo de cozinha, máquinas de cortar cabelo, panelas, entre outros, que garantem uma economia na prestação de serviços, ou seja, não são prioritariamente produtos adquiridos no lado boliviano para revenda direta.

Muitos moradores de Corumbá (brasileiros ou bolivianos) também utilizam suas casas como depósito de mercadorias dos feirantes por estarem situados em ruas próximas das itinerantes feiras de rua ou da antiga Feira Bras-Bol. A partir dessa situação abrem-se importantes questões relativas às relações entre casa, família e comércio, através da hibridação dos espaços da rua e dos tipos de comércio feitos nas próprias casas, "protegidos" do espaço público da rua e dos controles do Estado e menos visíveis para a população, o que reforça a visibilidade da atividade informal das feiras e dos comércios de rua, em que predominam os bolivianos.

Outro fator que explica a predominância dos comerciantes bolivianos no comércio de rua é o fato de que a moeda boliviana vale menos do que 
o real $(\mathrm{R} \$)^{9}$ e, assim, esses comerciantes bolivianos, principalmente os que vivem do outro lado da fronteira, conseguem não apenas um lucro maior nas vendas, mas também impedir a concorrência de comerciantes brasileiros, que não podem baixar tanto seus preços. De acordo com outro comerciante brasileiro em Corumbá: "não dá pra competir com os bolivianos. Eles são que nem praga, que nem formigas... invadem mesmo... pra eles qualquer real é dinheiro... a moeda deles lá não vale nada... com $\mathrm{R} \$ 1$ eles compram coisas do outro lado...".

A presença e a permanência desses comerciantes informais bolivianos acabam beneficiando também os consumidores, em especial os de baixa renda em Corumbá, que dependem desse comércio fronteiriço para adquirir os mais variados produtos, desde roupas, produtos eletrônicos, fraldas até hortaliças a preços mais acessíveis. É importante lembrar que, pelo fato de Corumbá estar distante dos centros produtores no Brasil, as mercadorias tendem a chegar com preços mais elevados em função dos fretes, da distância de Corumbá de centros produtores e distribuidores de mercadorias.

Retomando Hannerz (1974), podemos pensar como se estabelecem as relações entre etnicidade e estratificação social a partir de sua vinculação com etnias e classes sociais nos Estados Unidos, o que contribui para o reforço dos estereótipos e das estigmatizações feitas pelos grupos dominantes na busca pelo controle dos recursos simbólicos e materiais. É assim que os bolivianos, situados nos estratos sociais mais baixos da sociedade corumbaense, cientes de que disputam espaço com setores dominantes na cidade, têm que levar em conta não apenas sua etnicidade, mas sua nacionalidade como fatores para sobreviver e para realizar atividades empreendedoras na cidade de Corumbá. Um exemplo dessa situação está na escolha de alguns bolivianos em retirar o "Documento Fronteiriço"10 numa tentativa simbólica de amenizar sua alteridade, adquirindo sobretudo direitos de moradia no lado brasileiro, cientes de sua condição étnica e nacional estigmatizada, tanto do ponto de vista legal quanto do simbólico.

Em geral, de acordo com Silva (2013), são os comerciantes informais aqueles que procuraram retirar o documento junto à Polícia Federal, sob a justificativa de que precisam se amparar em documentos que legalizem sua situação no Brasil: "quanto mais documento, melhor". Além disso, este autor ressalta o papel dos mediadores, sejam os do Consulado boliviano, sejam os da Associação dos Comerciantes da Feira Bras-Bol, incentivando as pessoas a retirar o referido documento. Este é um exemplo de como a etnicidade e a nacionalidade, como formas de organização social, podem fomentar a ações de solidariedade e as estratégias de sobrevivência na fronteira a partir de um documento que garante uma identidade formalizada. 
Os bolivianos, em Corumbá, podem ser pensados numa analogia com o "estrangeiro" que, na definição de Simmel (1971), não é um indivíduo que passa por uma localidade, como o viajante eventual, mas é alguém que "chega hoje e fica amanhã" (Simmel 1971:143). Há, portanto, uma condição sociológica específica do boliviano, enquanto estrangeiro, como aquele que faz parte da cidade, mas ao mesmo tempo está fora dela e a confronta (e é confrontado por ela, em grande medida), gerando tensões nesse status ambíguo. Esta posição do estrangeiro se torna ainda mais aguda justamente quando ele se estabelece definitivamente nesse novo lugar. Esses indivíduos não são vistos por uma parcela da população de Corumbá como legítimos moradores do lugar, o que implica a própria mobilidade potencial desse grupo, como se percebe nas trajetórias pessoais dos comerciantes bolivianos desde o altiplano, passando por Santa Cruz de La Sierra, pela fronteira, em Corumbá, chegando até São Paulo.

De acordo com Simmel, em toda a história da humanidade é a atividade comercial que permite que o estrangeiro, como um mercador, possa viver em um lugar distante de sua origem. É assim que o boliviano se insere em Corumbá, trazendo mercadorias que não são produzidas na região, estabelecendo redes que se estendem para longe da fronteira, o que, aliás, permite sempre um dinamismo e uma criatividade que outras atividades produtivas, como a agricultura, por exemplo, não possuem (os próprios "árabes" da cidade de Corumbá se estabeleceram na fronteira com o comércio).

Além disso, como afirma Simmel, o estrangeiro ocupa um espaço específico de trabalho, que não vai ser preenchido, em geral, por outros indivíduos locais. Os bolivianos, porém, passaram a migrar para a fronteira e para a cidade de Corumbá, sobretudo a partir da década de 1990, como revendedores de roupas "Made in China", o que progressivamente os colocou na posição de competidores com os lojistas formalizados da cidade que, em sua maioria, são de origem árabe (sírios, libaneses e palestinos). Pode-se considerar que os "árabes", estabelecidos econômica e politicamente há algumas gerações em Corumbá, já não se consideram "estrangeiros", adotando em alguns momentos a identidade de "brasileiros" ou "corumbaenses", passando os caracteres negativos dessa condição de "forasteiro" aos bolivianos. Foi precisamente essa relação intrínseca entre o estrangeiro e a atividade comercial que permitiu aos "árabes" e aos bolivianos viverem em Corumbá, onde as demais posições econômicas e os postos de trabalho já se encontravam ocupados por residentes e locais. A própria fronteira como um lugar propício aos negócios, pelo "diferencial fronteiriço" (diferentes moedas e legislações), se torna um local atrativo para os migrantes e os comerciantes. 
Observamos também que, na medida em que alguns bolivianos se tornam empreendedores, patrões de si mesmos e começam a lucrar e a ascender socialmente, aumenta o sentimento de rivalidade com setores comerciais estabelecidos. Tanto os setores comerciais concorrentes em Corumbá (sobretudo do comércio formal) quanto o Estado (em todas as suas esferas) passam a explicitar esse conflito e o incômodo com a situação, buscando reforçar os controles, exigindo a tributação devida sob a hegemonia dos discursos da legalidade e o reforço da condição do "estrangeiro". Além disso, é preciso dizer que a maioria dos bolivianos não vota no Brasil, tornando-se "invisíveis" aos olhos dos políticos locais, que não veem o grupo como um possível nicho eleitoral. De outro lado, percebemos que há uma resistência por parte dos bolivianos - a partir de estratégias de sobrevivência em torno da sua coesão social e da sua proteção social - no que diz respeito às suas interações cotidianas e aos seus mediadores (ethnicbrokers) e organizações étnico-nacionais, como o Centro Boliviano-Brasileiro, o Consulado Boliviano em Corumbá, e suas associações, como a Associação de Comerciantes da Feira Bras-Bol.

As vinculações étnicas e/ou nacionais também contribuem para promover cotidianamente o "recrutamento" de trabalhadores, a partir de redes de parentesco e localidade desde a Bolívia, principalmente do altiplano, para Corumbá (Paes de Andrade 2014). Em inúmeras entrevistas e conversas informais, ao perguntarmos aos bolivianos como vieram para Corumbá, a maioria responde que se mudou por causa da vinda de parentes ou mesmo de vizinhos. Como eles "fizeram a vida" na fronteira, convenceram os demais a vir para a região onde já estavam estabelecidos. Há na cidade de Corumbá, portanto, a predominância de trabalhadores do altiplano que passaram a controlar, em grande medida, o comércio informal da cidade, assim como do outro lado da fronteira, o que aponta para estudos futuros a respeito desse ethos empreendedor e comerciante, centrado nos valores do trabalho e da poupança, vinculado à etnicidade e aos laços de parentesco na Bolívia. De acordo com Guaygua (2009), o parentesco andino, considerado pelo autor como um "parentesco transnacional", é o tecido social que vai estruturar as redes migratórias na Bolívia:

No mundo andino, concebe-se a "família" como o espaço no qual os distintos membros compartilham obrigações e estabelecem relações de reciprocidade e solidariedade. Nesse sentido, a família funciona como uma rede de relações de parentesco, que facilita e dá suporte ao processo migratório, com um papel central na hora de superar as condições adversas de sobrevivência dos integrantes do núcleo familiar. Neste sentido, a família andina em ambas as 
cidades está longe de ser uma instituição social imutável e alheia à realidade que a rodeia. Através de uma variedade de mecanismos se transforma e adapta, desafiando mudanças sociais, concepções tradicionais e fronteiras nacionais para continuar sua função de reprodução social diante da separação de seus membros (Guaygua 2009:1).

As relações de etnicidade podem prover, portanto, os "recursos extraterritoriais", nas palavras de Hannerz (1974), a partir dos quais se estabelecem relações com os locais de origem na Bolívia, seja no envio de mercadorias para o Brasil, seja nas remessas de dinheiro para "casa", ou na chegada de novos imigrantes para a fronteira, por exemplo.

\section{Considerações finais: controle, vigilância e exclusão social na fronteira}

Resta saber quais os efeitos políticos dessas hierarquizações, objetivando os discursos de poder que têm efeitos reais na vida das pessoas na fronteira. Nos últimos anos, percebemos uma presença cada vez mais ostensiva do Estado brasileiro, preocupado com os crimes fronteiriços e com sua soberania, nas áreas de fronteira, entendida nessas políticas federais apenas do ponto de vista da defesa e da segurança nacional e não como áreas de convivência e de interdependências culturais, sociais, políticas e econômicas. Ao longo do tempo, a presença dos comerciantes bolivianos e principalmente do comércio das roupas "não tributadas" têm fomentado ações do poder público, influenciado tanto por demandas políticas locais, sobretudo da Associação Comercial de Corumbá, quanto por demandas nacionais de segurança na fronteira e que visam coibir a entrada de produtos não tributados no Brasil. Destacamos entre as medidas do governo federal, a criação e a implantação do Plano Estratégico de Fronteiras (PEF), a partir de 2011, que prevê uma série de ações e medidas no sentido de reforçar a vigilância e o monitoramento das fronteiras brasileiras e que tiveram grande impacto local, inclusive com o aumento do efetivo do aparato de segurança, com a presença ostensiva da Força Nacional na cidade.

Além disso, foi implantado o Gabinete de Gestão Integrada de Fronteira (GGIFRON), da Secretaria de Estado de Justiça e Segurança Pública Sejusp/MS, responsável pela gestão integrada das forças de segurança na fronteira para o combate aos "crimes fronteiriços". Essas tecnologias de poder atuam sobre a circulação de pessoas e mercadorias na fronteira, "governamentalizando"11 e disciplinando não apenas os moradores dessas regiões, 
sobretudo aqueles que dependem da fronteira para sobreviver, mas também os próprios funcionários do Estado e outros segmentos sociais (Foucault 1979).

Sob o paradigma da legalidade e da segurança nacional amparado pelo direito, esses dispositivos fronteiriços proveem a captação de recursos privados e públicos para financiar projetos de intervenção (como foi o caso do fechamento da feira Bras-Bol), de operações de vigilância na fronteira e, mesmo, de obtenção de lucro a partir dessa política de securização (empresas de segurança, fabricantes de armas, "drones" de vigilância e todo o aparato de tecnologia de vigilância). Esses dispositivos operam sob a justificativa da segurança pública local e da defesa nacional nas fronteiras, como discursos produtores de "verdades" e que têm como efeitos o controle efetivo e a hierarquização de pessoas na fronteira, a partir de critérios de classificação sociais, étnicos e nacionais. É assim que se torna necessário compreender de que forma são postos em ação esses "dispositivos fronteiriços" de controle da população (práticas, discursos, técnicas, saberes), para entendermos a articulação entre vários agentes e agências que atuam na fronteira, aí gerando conhecimento e administrando a população que habita essa região, com base em diversos princípios de legitimidade.

A ideia da fronteira como limite e como área de segurança nacional é muito importante para a história de Corumbá, cujo evento simbólico e histórico mais significativo foi a sua ocupação pelos paraguaios na Guerra da Tríplice Aliança (entre 1865 e 1867), fato que gerou a posterior ocupação militar efetiva da região. Marcia Anita Sprandel (2005) apresenta uma genealogia sobre os estudos de fronteiras e limites no Brasil a partir da proclamação da República, demonstrando como as diversas publicações de intelectuais, geógrafos, diplomatas, militares, ou seja, de uma "minoria intelectualizada e ligada aos aparelhos de poder", contribuíram desde os discursos, calcados na geopolítica, para a formação do Estado nacional no Brasil, não apenas na demarcação dos limites, mas principalmente na inculcação de um ideário nacional. Identificamos a importância desses discursos debatidos pela autora, principalmente os que se referem à ideia de uma fronteira brasileira "definitivamente demarcada" e militarizada, aos projetos de "nacionalização" das fronteiras brasileiras, ou à concepção de fronteira como "foco de tensão" entre países.

O texto de Sprandel nos instiga a pensar sobre a "permanência do pensamento geopolítico nos meios militares e diplomáticos nacionais" (Sprandel 2005:154) que são reatualizados nas políticas públicas atuais, sobretudo em torno da questão da segurança nacional, cujos efeitos sociais analisamos neste artigo. A significativa presença militar na região (18 ${ }^{\mathrm{a}}$ Brigada de Infantaria de Fronteira, com sede em Corumbá, e o $6^{\circ}$ Distrito Naval, situado 
em Ladário) contribui para a eficácia, a permanência e a difusão desses discursos e dessas práticas na região.

O Estado, como afirmam Das e Poole (2008), não tende a se desarticular ou a se debilitar em suas margens territoriais ou sociais, muito pelo contrário. De acordo com as autoras, nessas margens se tornam mais visíveis os pressupostos necessários para o funcionamento do Estado, que aí continuamente redefine seus modos de governar, legislar e de controlar tanto o território quanto as populações. Nesse sentido, nos interessa pensar como o Estado põe em prática mecanismos que podem garantir ou deslegitimar as identidades na fronteira, tendo como símbolo paradigmático o "posto de controle", "como espaço cheio de tensão no qual os pressupostos acerca da segurança, da identidade e dos direitos podem ser repentinamente e, às vezes, violentamente negados" (Das \& Poole 2008:24).

Desde 2009, analisamos, a partir dos eventos que estudamos etnograficamente, o que consideramos ser um fechamento progressivo da fronteira para os trabalhadores bolivianos na cidade de Corumbá (como efeito dos dispositivos fronteiriços) e o reforço das hierarquias sociais em função da reificação dos discursos de pertencimento nacional e de exclusão étnica. Segue uma breve apresentação cronológica desses eventos recentes, que servem para demonstrar os efeitos reais do poder onde ele é exercido na prática: no dia a dia da fronteira.

Em 2009, houve a operação Bras-Bol, da Polícia Federal e da Receita Federal, que na véspera do Natal apreendeu as mercadorias da feira Bras-Bol (que funcionou por cerca de 20 anos em Corumbá), criminalizando as atividades da feira. Esta operação sem precedentes na cidade, por sua dimensão e violência simbólica, abriu caminho para a deslegitimação progressiva do trabalho informal na cidade sob o paradigma da legalidade (Costa 2010), o que veio a desembocar no fechamento definitivo da feira no ano de 2013.

No ano de 2010, acompanhamos o conflito entre taxistas brasileiros e taxistas bolivianos e a regulação do espaço da rua pela Prefeitura de Corumbá, a partir da demanda do sindicato dos taxistas de Corumbá (Costa 2014). Um dos efeitos dessas medidas foi a restrição da liberdade de ir e vir na fronteira, com a visível diminuição de carros com placa da Bolívia rodando na cidade de Corumbá e a afirmação de um pressuposto de que os bolivianos que podem circular na cidade são aqueles que têm alguma "utilidade" para Corumbá, ou seja, são apenas aqueles que abastecem a cidade, sem os quais não haveria as feiras e a venda de hortaliças.

Em 2011 (ver Costa 2011), houve um protesto na fronteira, no lado boliviano, pedindo a negociação do governo boliviano com autoridades brasileiras, criticando a Portaria 440 da Receita Federal do Brasil, que restringiu o 
trabalho dos sacoleiros e diminuiu consideravelmente o comércio em Puerto Quijarro. Tal manifestação também teve caráter simbólico, ao denunciar o preconceito de que são vítimas os bolivianos na fronteira e em Corumbá.

No ano de 2013, entre maio e junho, aconteceram duas operações de repressão ao comércio informal na cidade de Corumbá de grandes proporções. A primeira delas foi o fechamento definitivo da "Feira Bras-Bol", a feirinha, no dia 16 de maio, e a outra foi a operação "No Caminho", deflagrada no dia 02 de junho, que fechou mais de 30 estabelecimentos comerciais, conhecidas como as "lojinhas de bolivianos" na cidade. No caso da Feira Bras-Bol, a interdição foi uma medida municipal; a operação "No Caminho", por sua vez, foi realizada pela Receita Federal, a Polícia Federal e pelo Exército brasileiro, demonstrando uma confluência de interesses de setores locais de Corumbá com políticas federais de controle e vigilância na fronteira. Essas práticas de controle e vigilância acabam por tornar explícitas as divisões nacionais e étnicas na fronteira, a partir das quais se estruturam as estratégias dos órgãos de governo, como a Polícia Federal, a Receita Federal, a Prefeitura de Corumbá e os critérios de inclusão e exclusão de grupos sociais na fronteira.

A pesquisa aqui apresentada procurou entender, portanto, quais os significados e as motivações estruturais que ordenaram esses eventos, demonstrando a eficácia do poder simbólico dessas classificações e desses discursos. A partir desta análise, observa-se que não se trata apenas de conjunturas locais (disputas pelo comércio local) ou nacionais (políticas de segurança na fronteira) que promoveram recentemente o recrudescimento do controle e a deslegitimação progressiva dos bolivianos e seus descendentes em Corumbá. Esses processos se baseiam também em estruturas simbólicas de longa duração construídas em torno de representações calcadas em antinomias como índios/brancos, brasileiros/estrangeiros, a partir das quais esses discursos e essas ações são postos em prática no presente.

Daí, novamente seguimos as pistas deixadas por Roberto Cardoso de Oliveira quando afirma que um momento privilegiado para estudar empiricamente o fenômeno da identidade é quando estas identidades estão "em crise", isto é, quando são defrontadas com situações de extrema ambivalência no interior de sistemas sociais (Cardoso de Oliveira 2006:8). Através, então, dos seus "descaminhos" é que podemos compreender os processos de construção e reconstrução identitários, pois esses momentos de crise, apresentados nos exemplos etnográficos de conflitos na fronteira, explicitam as relações de poder, assim como as representações de si e dos outros. A partir dessa leitura, entendemos que a região de fronteira entre Estados nacionais torna mais visíveis essas crises identitárias, o que pode contribuir, empiricamente, para a análise de tais processos, nos quais se articulam identidade, etnicidade e nacionalidade. 
A passagem dos modelos teóricos das áreas de contato interétnico no interior do país para o entendimento do contato social nas fronteiras gera debates muito interessantes e provocadores. Um dos principais aspectos que permitem este diálogo, em nosso ponto de vista, está em pensar o papel do Estado-nação em interação com grupos sociais distintos em seu território e quais conflitos e processos sociais decorrem dessa relação assimétrica de poder, não apenas entre o Estado e os moradores, mas entre grupos étnicos e nacionais. Compreender como a identidade se reconstrói nesses cenários ambíguos de fronteira, quais discursos e representações são produzidos e quais os efeitos sociais, morais e políticos desses processos são desafios em nossas pesquisas. Essas investigações devem estar pautadas na busca constante de trabalhar com um aparato teórico, que tem como efeito moral e social o rompimento dos preconceitos e a explicitação de formas de dominação, na tradição antropológica, de apontar caminhos para o respeito à diferença e para a consideração e o reconhecimento do outro em sua dignidade.

Recebido em 16 de julho de 2014

Aprovado em 12 de fevereiro de 2015

Gustavo Villela Lima da Costa é Professor Adjunto de Antropologia na Universidade Federal do Mato Grosso do Sul. E-mail: <guvillela75@ig.com.br>

\section{Notas}

1 "A identidade contrastiva parece se constituir na essência da identidade étnica, i.e., na base da qual esta se define. Implica a afirmação do nós diante dos outros. Quando uma pessoa ou um grupo se afirma como tal, o faz como meio de diferenciação em relação a alguma pessoa ou grupo com que se defronta. É uma identidade que surge por oposição. Ela não se afirma isoladamente" (Cardoso de Oliveira 2003:120).

${ }^{2}$ Agradeço a generosa leitura crítica e as sugestões feitas pela antropóloga e professora Dra. da UNIOESTE, Regina Coeli Machado e Silva. Agradeço também os debates e os diálogos com o antropólogo Álvaro Banducci Junior, professor Dr. da UFMS. Eventuais problemas e falhas deste artigo são, porém, de minha inteira responsabilidade. 
${ }^{3}$ Ladário, fundada em 1778, possui aproximadamente 20 mil habitantes, e é um enclave no município de Corumbá. Considera-se informalmente que Ladário e Corumbá formam uma área conurbada, já que a distância entre os dois centros é de apenas 6 km, mesma distância entre os portos municipais.

${ }^{4}$ De acordo com Norbert Elias, "o convívio dos seres humanos em sociedades tem sempre, mesmo no caos, na desintegração, na maior desordem social, uma forma absolutamente determinada. É isso que o conceito de figuração exprime. Os seres humanos, em virtude de sua interdependência fundamental uns dos outros, agrupam-se sempre na forma de figurações específicas [...]. Essas figurações possuem peculiaridades estruturais e são representantes de uma ordem particular [...]" (Elias 2006:26) .

${ }^{5}$ Como este artigo procura dar um sentido teórico mais abrangente a pesquisas anteriores, utilizo novamente alguns exemplos etnográficos e entrevistas mais significativos publicados em outros artigos e que ganham aqui novas interpretações, junto com a maior parte de material inédito.

${ }^{6}$ De acordo com Telles (2009), esses atores sociais são portadores de "competências circulatórias (quer dizer, saber passar pelas fronteiras, contornar as restrições, os controles e as fiscalizações), transformando-se em atores de amplas transferências internacionais de mercadorias" (Telles 2009:160).

${ }^{7}$ Ao todo contabilizamos mais de 20 barracas que vendem roupas (em geral trazidas da Bolívia) nas feiras de rua e apenas uma delas tinha como dono um brasileiro.

${ }^{8}$ Para Giddens, "os membros de um grupo minoritário estão em desvantagem em relação à maioria da população e têm um certo sentido de solidariedade de grupo, de pertencerem ao mesmo grupo. A experiência de serem objeto de preconceito e discriminação amplifica normalmente os sentimentos de lealdade e interesses comuns" (Giddens 2008:250).

${ }^{9}$ Mesmo com as variações eventuais de câmbio, um real equivale a três bolivianos: 1R $\$$ (um real) = 3Bs\$ (três bolivianos)

${ }^{10}$ Em 12 de janeiro de 2009 foi promulgado pelo governo brasileiro, através do Decreto $n^{\circ}$ 6.737, o "Acordo entre o Governo da República Federativa do Brasil e o Governo da República da Bolívia para Permissão de Residência, Estudo e Trabalho a Nacionais Fronteiriços Brasileiros e Bolivianos", que reconhece que "as fronteiras que unem os dois países constituem elementos de integração de suas populações" e permite, em seu Artigo I, "ingresso, residência, estudo, trabalho, previdência social e concessão de documento especial de fronteiriço a estrangeiros residentes em localidades fronteiriças". A relação de vinculação das cidades fronteiriças, neste decreto, é a seguinte: Brasileia (Brasil) a Cobija (Bolívia); Corumbá (Brasil) a Puerto Suarez (Bolívia); Cáceres (Brasil) a San Matías (Bolívia) e Guajaramirim (Brasil) a Guayaramirim (Bolívia). Este documento é denominado localmente apenas como "Documento Fronteiriço" e passou a ser utilizado, sobretudo, por comerciantes informais de origem boliviana em Corumbá. 
${ }^{11} \mathrm{O}$ conceito de governamentalidade é definido por Foucault como "o conjunto constituído pelas instituições, procedimentos, análises e reflexões, cálculos e táticas que permitem exercer esta forma bastante específica e complexa de poder, que tem por alvo a população, por forma principal de saber a Economia Política, e por instrumentos técnicos essenciais os dispositivos de segurança" (Foucault1979:293).

\section{Referências bibliográficas}

BARTH, Fredrik. 2000. "Os grupos étnicos e suas fronteiras". In: O guru e o iniciador e outras variações antropológicas. Rio de Janeiro: Contra Capa. pp. 25-68.

BENENCIA, Roberto. 2004. "Trabajo y prejuicio. Violencia sobre inmigrantes bolivianos en la agricultura periférica de Buenos Aires". Revue Européenne de Migrations Internationales, 20(1):97-118.

BENENCIA, R. \& KARASIK, G. 1996. Inmigración limítrofe: los bolivianos en Buenos Aires. Biblioteca Política Argentina, n. 482. Buenos Aires: Centro Editor de América Latina.

BETRISE Y NADALI, Débora. 2007. “Inmigración y discriminación en la frontera argentino-paraguaya". Migr. Inter [online], 4(1):141-164. Acesso em: $15 / 09 / 2014$.

BOURDIEU, Pierre. 1989. O poder simbólico. Rio de Janeiro: Bertrand Brasil. CARDOSO DE OLIVEIRA, Roberto. 1976. Identidade, etnia e estrutura social. São Paulo: Livraria Pioneira Editora. - 2003. "Identidade étnica, identificação e manipulação". Sociedade e Cultura, 6(2):117-131, jul./dez. · 2005. "Introdução". In: Roberto Cardoso de Oliveira \& Stephen Baines (orgs.), Nacionalidade, etnicidade em fronteiras. Brasília: Editora UnB. pp. 9-20.
_.2006. Caminhos da identidade. Ensaios sobre etnicidade e multiculturalismo. São Paulo / Brasília: Editora Unesp / Paralelo 15.

COSTA, Gustavo V. L. 2010. "As fronteiras da identidade em Corumbá-MS: significados, discursos e práticas". In: G. V. L. da Costa; E. A. Costa \& M. A. M. Oliveira (orgs.), Estudos fronteiriços. Vol. 1. 1 ${ }^{\mathrm{a}}$.ed. Campo Grande: Editora UFMS. pp. 69-98.

. 2011. "'Fechar a fronteira': rituais, estratégias políticas e mobilização social em Arroyo Concepción/ Puerto Quijarro - Bolívia". In: G. V. L. da Costa; E. A. Costa \& M. A. M. Oliveira (orgs.), Fronteiras em foco. Série Fronteiras 3. Campo Grande: Editora UFMS .pp. 149-170.

. 2013a. "O muro invisível: a nacionalidade como discurso reificado na fronteira Brasil Bolívia". Tempo Social, 25:141-156. . 2013b. "A Feira Bras-Bol, em Corumbá-MS: notas sobre o comércio informal na fronteira Brasil-Bolívia". Contemporânea - Revista de Sociologia da UFSCar, 3:467-489.

-2014. "Táxis na fronteira: disputas pelo espaço da rua em Corumbá / Ladário (Brasil) Puerto Quijarro/ Puerto Suarez (Bolívia)". In: Antônio Rafael Barbosa; 
Brígida Renoldi \& Marcos Veríssimo (orgs.), (I)Legal: etnografias em uma fronteira difusa. Vol. 1. 1 $1^{\text {a }}$.ed.Niterói: Editora da UFF. pp. 141-161.

DAS, Veena \& POOLE, Deborah. 2008. "El Estado y sus márgenes. Etnografías comparadas". Cuadernos de Antropología Social, 27:19-52.

DOUGLAS, Mary. 2012. Pureza e perigo. São Paulo: Perspectiva.

ELIAS, Norbert. 2006. Escritos \& ensaios 1. Estado, processo, opinião pública. Rio de Janeiro: Jorge Zahar Editores. FOUCAULT, Michel. 1979. A microfísica do poder. Rio de Janeiro: Graal.

GIDDENS, Anthony. 2008. Sociologia. Lisboa: Fundação Calouste Gulbenkian. GRIMSON, Alejandro.1997. "Relatos de la diferencia y la igualdad: bolivianos en Buenos Aires". Nueva Sociedad, Comunicación culturas e identidades en el fin de siglo, 147:96-107, Enero-Febrero.

2003. La nación en sus límites: contrabandistas y exilados en la frontera Argentina-Brasil. Barcelona: Gedisa Editorial.

GUAYGUA, Germán. 2009. "Parentesco andino en la constitución de trayectorias y redes migratórias hacia España". Tinkazos, 12(26):147-162.

HANNERZ, Ulf. 1974. "Ethnicity as opportunity in urban America". In: Abner Cohen (org.), Urban ethnicity. London/ New York/Sydney/Toronto/Washington: Routledge. pp. 37-76.

HARDT, Michael \& NEGRI, Antonio. 2000. Império. Buenos Aires / Barcelona / México: Paidós.

KARASIK, Gabriela. 2012. "Marcas bolivianas y jujeñas en la cultura. Reflexiones sobre la presencia boliviana en Jujuy". Anales de la Reunión Anual de Etnología, 24:115-126.

KARASIK, G. \& BENENCIA, R. 1998-1999. "Apuntes sobre la migración fronteriza.
Trabajadores bolivianos en Jujuy". Estudios Migratorios Latinoamericanos, Año 13/14, 40-41:569-594.

MORAES. Lourival Monteiro. 2012. Bilinguismo e jogo de identidades na região de fronteira: a escola Eutrópia Gomes Pedroso, de Corumbá. Dissertação de Mestrado, Programa de Pós-Graduação em Estudos Fronteiriços, Universidade Federal de Mato Grosso do Sul.

OliVeirA, Giovanni França. 2013. "O policial de fronteira e o policial da fronteira: considerações sobre a distinção de pessoa e indivíduo nas práticas policiais de combate e repressão no varejo de drogas em Corumbá na fronteira com a Bolívia". Anais do XVI Congresso Brasileiro de Sociologia. Mimeo.

PAES DE ANDRADE, Pedro R. 2014. Bolivianos do altiplano em Corumbá: trajetórias migratórias e experiências. Dissertação de Mestrado, Programa de Pós-Graduação em Antropologia, Universidade Federal da Grande Dourados. PIMENTA, José. 2011. "'Parentes Diferentes': etnicidade e nacionalidade entre os Ashaninka na fronteira Brasil-Peru". Anuário Antropológico, 2011(I):91-119. Brasília: Tempo Brasileiro.

RIBEIRO, M. L. O. 2011. O idioma e a Escola de Fronteira como fatores de inclusão social de crianças e adolescentes em Corumbá (BR) e Puerto Quijarro (BO).Dissertação de Mestrado, Programa de Pós-Graduação em Estudos Fronteiriços, Universidade Federal de Mato Grosso do Sul.

SILVA, Cristhian Teófilo da. 2007. "Nacionalidade e etnicidade em fronteiras". Horizontes Antropológicos, 13:341-346. SILVA, Fabio M. 2013. Documento Especial Fronteiriço: acordos internacionais e desacordos locais. Dissertação de Mestrado, Programa de Pós-Graduação em Estudos Fronteiriços, Universidade Federal de Mato Grosso do Sul. 
SIMMEL, Georg. 1964. Conflict \& the web of group-affiliations. New York/London/Toronto/Sydney/Singapore: The Free Press. - 1971. On individuality and social forms. Chicago / London: The University of Chicago Press.

SPRANDEL, M. A. 2005. "Breve genealogia sobre os estudos de fronteiras e limites no Brasil". In: Roberto Cardoso de Oliveira \& Stephen Baines (orgs.), Nacionalidade, etnicidade em fronteiras. Brasília: Editora UnB. pp. 153-204. TELLES, Vera da Silva. 2009. "Ilegalismos urbanos e a cidade". Novos Estudos Cebrap [online], 84:153-173.

VILA, Pablo. 2000. Crossing borders, reinforcing borders. Social categories, metaphors and narrative identities on the U.S. - Mexico frontier. Austin: The University of Texas Press. 
Resumo

A partir de pesquisas etnográficas realizadas desde 2009 em Corumbá, na fronteira Brasil-Bolívia, procuro compreender alguns aspectos das relações de poder que se tornam mais visíveis por meio da análise dos conflitos sociais entre brasileiros e bolivianos. Para organizar os principais temas envolvidos nessa pesquisa, o artigo está dividido em três partes. Na primeira, abordo as interseções entre nacionalidade e etnicidade como critérios de classificação social na fronteira e as representações estigmatizantes sobre os bolivianos produzidas no lado brasileiro. Na segunda, discuto as estratégias de trabalho dos bolivianos em Corumbá em torno do comércio informal, relacionando etnicidade e nacionalidade com as oportunidades de trabalho e as formas de organização social. Por fim, nas considerações finais, busco compreender quais os efeitos sociais da deslegitimação progressiva dos bolivianos no lado brasileiro, manifestados nas políticas de controle e vigilância na fronteira, a partir da criminalização das práticas de trabalho informal.

Palavras-chave Fronteira, Nacionalidade, Etnicidade, Conflito, Corumbá.

\section{Abstract}

Through ethnographic studies conducted since 2009 in Corumbá, in the BrazilBolivia border, I seek to unravel some aspects of power relations that become more visible through the analysis of social conflicts between Brazilians and Bolivians. To organize the main issues involved in this research, the article is divided into three parts. In the first part, I will discuss the intersections between nationality and ethnicity as criteria for classification at the border and the pejorative representations of Bolivians produced on the Brazilian side. In the second part, I discuss the work strategies of Bolivians in Corumbá in the informal economy, relating ethnicity and nationality with job opportunities and forms of social organization. Finally, the last part of the paper seeks to understand the social effects of the progressive delegitimization of Bolivians on the Brazilian side, manifest in political control and surveillance at the border, and through the criminalization of informal work practices.

Key words Border, Nationality, Ethnicity, Conflict, Corumbá. 